\title{
Effect of phenol concentrations on the condensation reaction during the liquefaction of waste woody materials with phenol
}

\author{
Q. Wang ${ }^{1}$, N. Mitsumura ${ }^{1}$, Q. Chen ${ }^{1}$, P. Apar $^{1}$, Q. Qian ${ }^{1}$, L. Gui ${ }^{1}$, \\ H. Niida ${ }^{1}$, H. Kurokawa ${ }^{1}$, K. Sekiguchi ${ }^{1} \&$ K. Sugiyama ${ }^{2}$ \\ ${ }^{1}$ Graduate School of Science and Engineering, Saitama University, Japan \\ ${ }^{2}$ Hachinohe National College of Technology, Japan
}

\begin{abstract}
The wood liquefaction technique using phenol is the developing method to utilize the waste woody materials for phenolic resin. However, the condensation reaction is one of the problems for popularizing the wood liquefaction technique. The lowering of the phenol concentrations in the wood liquefaction process is thought to be the cause of the condensation reaction. To find the reason and examine our hypothesis, woody meals (sawdust) were liquefied under the different conditions using phenol in the presence of sulfuric acid as a catalyst. Under the intensive liquefaction conditions such as higher reaction temperatures and more catalyst contents and smaller particle sizes of woody meal, remarkable condensation reaction was observed. It was found that the phenol concentrations were approximately $8 \%$ lower at the end of the reaction and became stable when the condensation reaction took place. It was indicated that the lowering of the phenol concentration suppressed the liquefaction reaction and prompted the condensation reaction. However, it was considered that the wood liquefaction also almost stopped when the condensation reaction was hardly observed. According to all results, it is suggested that the cause of the condensation reaction is not only due to the lowering of the phenol concentrations but also due to the decomposing of liquefied woody constituents into low molecules under the intense liquefaction.
\end{abstract}

Keywords: waste woody materials, liquefaction, phenol, condensation mechanism, high performance liquid chromatography. 


\section{Introduction}

Recently, large amount of unutilized waste woody materials is produced around the world. For example, most forest thinning, one of the major waste woody materials, are discarded in forests in Japan. Because they are reusable, it is necessary to substitute these abundant woody materials for the fossil resources in the area such as materials and fuels. However, woody biomass materials are poor in workability because they have little plasticity. If that kind of property can be added, the application area of woody materials will be expanded. Based on that background, increasing attentions are paid to liquefaction technology of woody materials using phenol. This technique is a solvolysis method to convert all of the woody constituents into liquid matter (so-called 'liquefied wood') through the reaction procedure with phenol using acid catalysts such as sulfuric acid under the suitable temperatures, which is called liquefaction. After that, woody constituents are degraded to low molecules which have similar reactivity as phenol. The liquefied wood can be used as raw materials producing phenolic resin which is one of the most popular plastic today. Some researches on making various kinds of phenolic resins such as moldings [1], foams [2] and fibers [3] have been reported. In our previous studies, the effects of the species of woody components and different acid catalysts on liquefaction products were investigated $[4,5]$.

However, there is the problem of popularizing the technique. That is the condensation reaction taking place during the liquefaction. This phenomenon is considered to be the polymerization of degraded woody compounds generated through the liquefaction reaction [6]. By the condensation reaction, high molecules are formed, which deteriorate the quality of phenolic resin. To inhibit the condensation reaction, much more phenol concentrations against woody materials are needed to be added to the liquefaction system [7]. However, the consumption of phenol has to be saved because it is made from exhaustible petroleum resources. Up to now, the cause and mechanism of the condensation reaction has not been figured out enough. It is important to understand the condensation mechanism to develop the suppression method for it. Thus, the objective of this study is to clarify the mechanism and processes of condensation reaction.

According to other studies, the liquefaction mechanism (without the condensation reaction) of woody constituents such as cellulose and lignin is considered to be as follows [8,9]. Firstly, woody constituents are degraded by acid catalyst and subsequently reactive carbocations are generated. Then, they react with phenol (phenolation) to produce phenolated compounds. After that, the above process and hydrolysis or others are carried out repeatedly to continue the liquefaction reaction. Here, the phenolation is seemed to be a process that hardly occurs when the concentration of phenol is low. In that case, the reactive carbocations might react with compounds other than phenol. They are thought to be nucleophilic compounds similar to phenol. That seems to be the initial condensation reaction. For example, the phenolated products might have nucleophilicity because they were found to have multiple combined phenols in 
their structure [8-11]. Zhang et al. indicated that in the liquefaction of cellulose, the decomposed fragments from cellulose condense via combined phenol of the phenolated compounds [7]. Also, phenolic compounds derived from the degradation of lignin are thought to play the major role on the condensation reaction [12]. In short, we suggest the possible mechanism of the condensation reaction as the following reason. That is, the lowering of the phenol concentrations would suppress the phenolation and prompt the condensation reaction which is the reaction between the carbocations and nucleophilic compounds other than phenol such as phenolated compounds and phenols derived from lignin decomposition. As this reason, in our study, we focused our research on the influence of liquefaction conditions such as phenol concentrations on the deal of the condensation reaction to confirm the above hypothesis.

\section{Experimental procedures}

\subsection{Materials}

Woody meals (or sawdust) of Japanese cedar (Cryptomeria japonica) were used as raw waste woody materials for the liquefaction. These waste woody materials were collected from the waste disposal plant of Saitama, Japan, and then sieved into given particle sizes $(<250 \mu \mathrm{m}, 250-500 \mu \mathrm{m}$ and 500-1,000 $\mu \mathrm{m})$ shown in table 1 and dried at room temperature for 12 hours before the liquefaction experiment. Sulfuric acid was used as a mineral acid catalyst. All other chemicals except methanol of HPLC grade were reagent grade.

Table 1: $\quad$ All reaction conditions of liquefaction carried out in this study.

\begin{tabular}{ccccc}
\hline $\begin{array}{c}\text { Run } \\
\text { No. }\end{array}$ & $\begin{array}{c}\text { Phenol charge } \\
\text { ratios*1 }\end{array}$ & $\begin{array}{c}\text { Acid catalyst } \\
\text { contents } \\
{[\%]^{* 2}}\end{array}$ & $\begin{array}{c}\text { Reaction } \\
\text { temperatures } \\
{\left[{ }^{\circ} \mathrm{C}\right]}\end{array}$ & $\begin{array}{c}\text { Woody meal } \\
\text { particle sizes } \\
{[\mu \mathrm{m}]}\end{array}$ \\
\hline 1 & $3: 1$ & 50 & 180 & $250-500$ \\
2 & $2: 1$ & 50 & 180 & $250-500$ \\
3 & $2: 1$ & 50 & 160 & $250-500$ \\
4 & $2: 1$ & 50 & 120 & $250-500$ \\
5 & $2: 1$ & 50 & 180 & $500-1,000$ \\
6 & $2: 1$ & 50 & 180 & $<250$ \\
7 & $2: 1$ & 40 & 180 & $250-500$ \\
8 & $2: 1$ & 10 & 180 & $250-500$ \\
9 & $3: 1$ & 10 & 120 & $500-1,000$ \\
10 & $2: 1$ & 30 & 180 & $250-500$ \\
11 & $2: 1$ & 30 & 180 & $<250$ \\
\hline
\end{tabular}

*1: Ratio of phenol and woody meals charged $(\mathrm{g} / \mathrm{g})$.

*2: Weight percentage of initial addition of woody meal. 


\subsection{Methods}

\subsubsection{Liquefaction of woody materials}

The liquefaction was carried out using $500 \mathrm{~mL}$ three necked flask equipped with a mechanical stirrer and reflux cooler. The reaction conditions are shown in table 1. In this study, for better comprehension, reaction conditions under higher reaction temperatures and catalyst contents, and smaller particle sizes of woody meal are defined as 'intensive', while these under lower reaction temperatures and catalyst contents, and larger particle sizes of woody meal are called as 'mild'. The given amounts of woody meal samples and phenol based on table 1 were charged into the flask and immersed in a preheated oil bath. Then sulfuric acid was added. The time of sulfuric acid charging was regarded as start time of reaction and the reaction was run for up to 300 minutes. The samples were taken from the flask several times during the process and put into vials. Then it was immersed in cold water to stop the reaction.

\subsubsection{Measurement of residue contents}

The deal of the reactions including the condensation reaction was evaluated by measuring the residue contents. The residues are the mixed matter of the unliquefied woody meal and the condensed matter which is polymerized to some extent. It is known that the residues amount decreases due to the liquefaction at the former stage of the reaction, while it increases at the later stage due to the condensation reaction. Therefore, the increase rate of the residue amount may reflect the deal of the condensation reaction. To measure the residue contents, the samples were diluted with excess methanol and filtrated using the glass fibre filters (GA-100 Toyo Roshi Kaisha, Co. Ltd.) under reduced pressure washing with methanol. The residues were dried in an oven at $105^{\circ} \mathrm{C}$ for 24 hours and then weighed. The residue content was defined as the percentage of weight of the residue to the weight of the charged woody meals.

\subsubsection{Measurement of phenol concentrations}

The concentration of phenol in the samples was measured using the high performance liquid chromatograph (HPLC) equipped with a detector of SPD10A (Shimadzu Co. Ltd.), a column of Wakosil-PAHs (Wako Co. Ltd.). The flow rate, the oven temperature and detection wavelength were $2 \mathrm{ml} / \mathrm{min}, 40^{\circ} \mathrm{C}$, $272 \mathrm{~nm}$ respectively. Methanol/ $\mathrm{H}_{2} \mathrm{O}(1: 2, \mathrm{v} / \mathrm{v})$ mixed solvent was used as the mobile phase. The samples were diluted by $0.1 \mathrm{wt} . \%$ by methanol/water $(4: 1$, $\mathrm{v} / \mathrm{v})$ mixed solvent for the measurement. Syringe filter $(0.45 \mu \mathrm{m}$, Toyo Roshi Kaisha Co. Ltd.) was used to remove the residues in the sample when the sample was injected.

\section{Results and discussions}

\subsection{Effects of various reaction conditions on the condensation reaction}

\subsubsection{Effect of phenol charge ratios on the condensation reaction}

Figure 1 shows the relationship between the residue contents and reaction time for different phenol charge ratios. As the result, the increase of residue contents 
were observed, indicating the condensation reaction easily occurred with less phenol charge ratios and was suppressed when much phenol was charged. The reason for that might be caused from the phenolation proceeded predominantly with much more phenol charging. Thus, it can be said that the result supported the hypothesis which the lowering of phenol concentration prompts the condensation reaction.

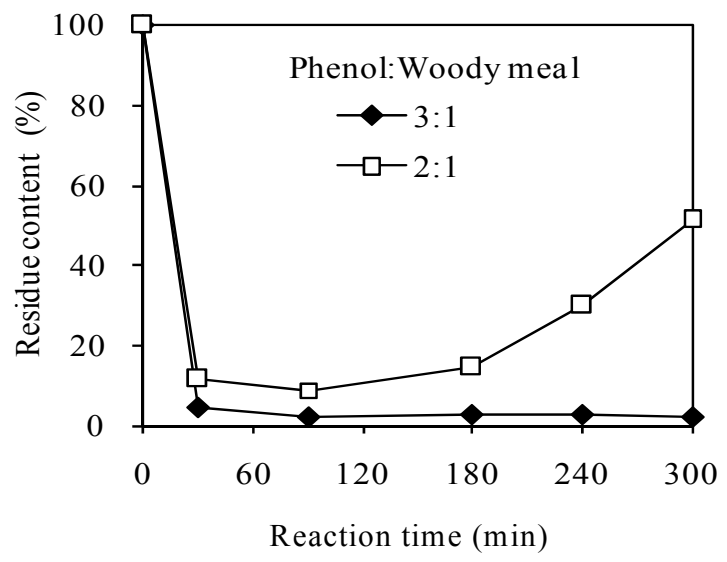

Figure 1: Residue contents for different phenol charge ratio varied with the reaction time reaction time. Other reaction conditions: catalyst contents; $50 \%$, reaction temperature; $180^{\circ} \mathrm{C}$, woody meal particle sizes; 250-500 $\mu \mathrm{m}$.

\subsubsection{Effect of reaction temperatures on the condensation reaction}

The residue contents for different reaction temperatures varied with the reaction time shown in figure 2. It was found that the residue contents increased in the late stage of reaction time in the case of $180^{\circ} \mathrm{C}$ and $160^{\circ} \mathrm{C}$. Meanwhile, the residue contents became stable in the case of $120^{\circ} \mathrm{C}$ after 90 minutes. That is, the higher reaction temperatures promoted the condensation reaction. It was considered that because higher reaction temperatures degraded the woody constituents severely, many carbocations were generated and phenol was consumed quickly. When the reaction temperature was $120^{\circ} \mathrm{C}$, the residues remained about $20 \%$. Accordingly, the condensation reaction is not likely to occur unless the woody constituents are intensively degraded to low molecules.

\subsubsection{Effect of catalyst contents on the condensation reaction}

The residue contents for different catalyst contents varied with reaction time were measured (figure 3). Much catalyst contents led more remarkable increase of residue contents. The reason is thought to be because of much generation of the carbocations and much consumption of phenol, similar to the experiment of different reaction temperatures discussed above. However, the most of woody constituents seemed to be degraded and liquefied in the case of $10 \%$ because the 


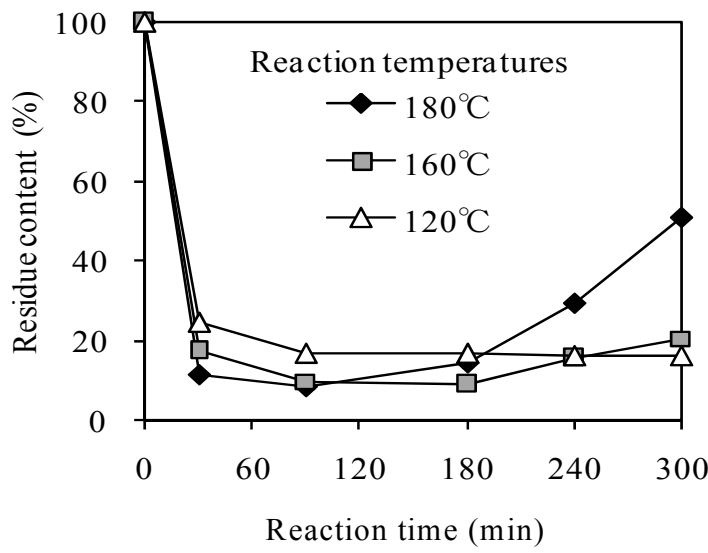

Figure 2: Residue contents for different reaction temperatures varied with the reaction time reaction time. Other reaction conditions: phenol charge ratio; $2: 1$, catalyst contents; $50 \%$, woody meal particle sizes; $250-500 \mu \mathrm{m}$.

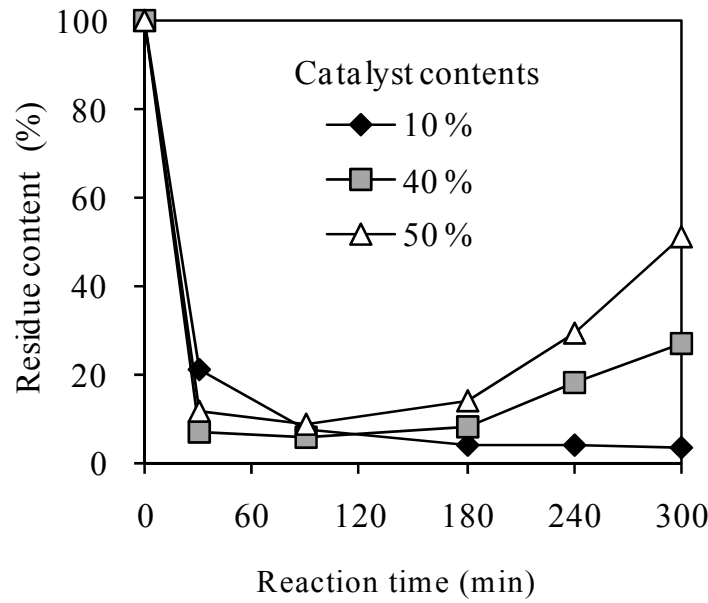

Figure 3: Residue contents for different catalyst contents varied with the reaction time. Other reaction conditions: reaction temperature $180^{\circ} \mathrm{C}$; phenol charge ratio; $2: 1$, woody meal particle sizes; 250 $500 \mu \mathrm{m}$.

residue contents reduced to less than $5 \%$ at $300 \mathrm{~min}$. This showed that despite degradation of woody constituents is considered to promote the condensation reaction, the relatively higher molecular weight products which exist in liquid part are not thought to contribute to the condensation reaction. 


\subsubsection{Effect of woody meal particle sizes on the condensation reaction}

Figure 4 shows the residue contents for different woody meal particle sizes varied with the reaction time. It was found that the condensation reaction occurred greatly with smaller woody meal particle. The reason is probably because phenol consumed quickly since the liquefaction reaction accelerated with smaller woody meal particle. Exactly, in the case of $500 \mu \mathrm{m}-1,000 \mu \mathrm{m}$, the time at which the residue contents begun to increase was later than other particle sizes. The similar tendency was also found in figure 3 .



Figure 4: Residue contents for different woody meal particle sizes varied with the reaction time. Other reaction conditions: reaction time; $180^{\circ} \mathrm{C}$, phenol charge ratio; $2: 1$, catalyst content; $50 \%$.

As observed above, the condensation reaction was likely to be observed under intense reaction condition where reaction temperatures and catalyst contents were higher, and woody meal particle sizes were smaller. On the other hand, it was already known that the liquefaction also becomes intense under these conditions [13]. Additionally, the same is considered to be true for the condition of the smaller woody meal particle sizes from the viewpoint of reaction efficiency. Therefore, it was shown that the intense liquefaction conditions lead the remarkable condensation reaction.

\subsection{Relationship between the condensation reaction and the phenol concentrations}

If the condensation reaction takes place, the consumption of phenol is thought to be inhibited because the condensation reaction might proceed instead of the phenolation. To show that, the residue contents and phenol concentrations varied with the reaction time under mild reaction condition was measured as shown in figure 5. As the result, the residue contents decreased gradually from the 
beginning of reaction time, indicating the liquefaction proceeded slowly. And, the phenol concentration also kept decreasing gradually, indicating phenol continued to be consumed due to the phenolation. Therefore, it was shown that the phenol concentration continued to decrease in the absence of the condensation reaction. In order to show that the lowering of the phenol concentration in the liquefaction would promote the condensation reaction, the phenol concentration with the condensation reaction and that without it were compared.

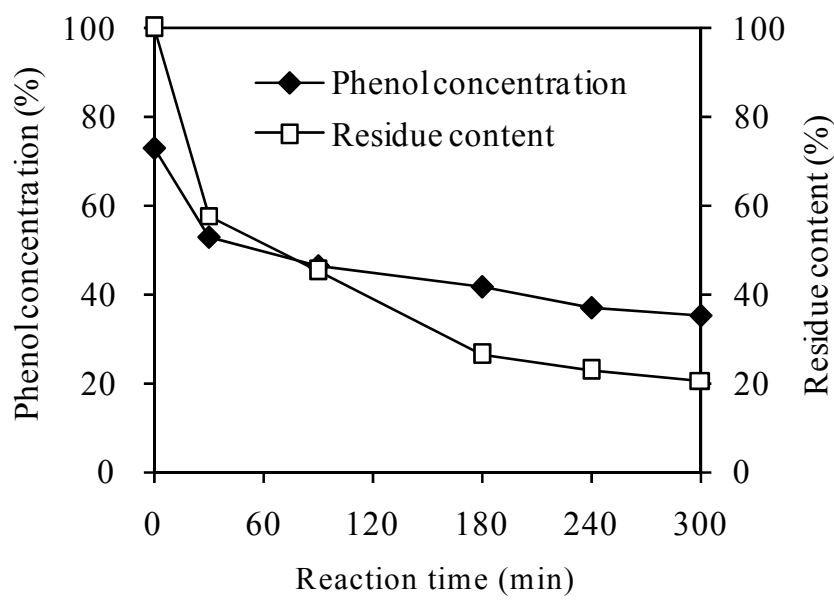

Figure 5: Residue contents and phenol concentrations varied with the reaction time. Reaction conditions: reaction temperature; $120^{\circ} \mathrm{C}$, phenol charge ratio; $3: 1$, catalyst contents; $10 \%$, woody meal particle sizes; $500-1,000 \mu \mathrm{m}$.

Figure 6(a) shows the residue contents for different woody meal particle sizes varied with the reaction time. The catalyst content was different from that of figure 4 . As a result, in the case of $<250 \mu \mathrm{m}$, the residue contents greatly increased from 90 minutes of reaction time, indicating the condensation reaction occurred. On the other hand, the increase of residue contents was hardly observed in the case of $250-500 \mu \mathrm{m}$. For these two conditions, the phenol concentration was measured (figure 6(b)). It was found that the phenol concentration was lower from beginning to end when the woody meal particle used was smaller. Maybe it was because the phenolation efficiently proceeded with smaller particle. Furthermore, the phenol concentration became stable after $180 \mathrm{~min}$ in that case. It indicated that the liquefaction was suppressed and instead the condensation reaction was promoted because of the lowering of the phenol concentration. However, in the case of $250-500 \mu \mathrm{m}$, the phenol concentration also became stable although the condensation reaction was hardly observed. That means neither the liquefaction reaction nor the condensation reaction was not taking place. The reason why the liquefaction was suppressed is considered to be 
because the phenol addition amount in this experiment was not enough. The question why there are the two cases that the condensation reaction occurs or not after the liquefaction stop due to lack of phenol concentration arose.
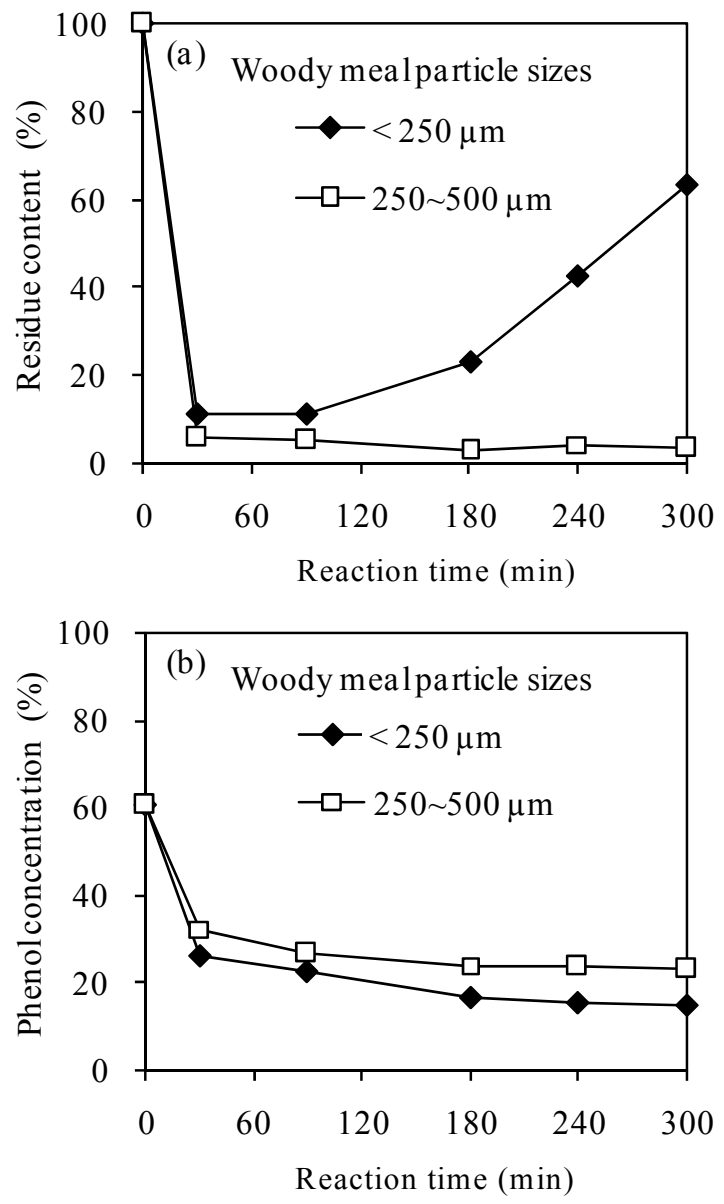

Figure 6: Residue contents (a) and the phenol concentrations (b) for different woody meal particle sizes varied with the reaction time. Other reaction conditions: phenol charge ratio; $2: 1$, reaction temperature; $180^{\circ} \mathrm{C}$, catalyst contents; $50 \%$.

When the woody meal particles are smaller, woody constituents are thought to be easily degraded in the liquefaction and lower molecules would generate. The condensation reaction is the polymerization of these degraded woody constituents. Therefore, it is inferred that smaller the degraded woody constituents, the more easily the polymerization may occur because the reactive sites of agents are easy to approach each other. Thus, in the case of 250-500 $\mu \mathrm{m}$, 
the condensation reaction did not occur maybe because the molecules of degraded compounds were larger molecules. In other words, although the condensation reaction is thought to be attributed to lowering of phenol concentration, the phenomenon would hardly occur unless the degraded woody constituents are degraded into lower molecules. Actually, the condensation reaction was not likely to occur under the mild reaction conditions, such as low reaction temperature and catalyst contents, and large particles of woody meal as shown in figure 3-figure 5.

\section{Conclusion}

The condensation reaction during liquefaction of woody material with phenol was considered to be caused by lowering of phenol concentration in the reaction.

It was found that the condensation reaction occurred remarkably under the intense reaction conditions such as higher reaction temperatures and catalyst contents, and smaller woody meal particle sizes. It was observed that in the case the condensation reaction was hardly observed, the time when the residue contents begun to increase was later than that in the case the condensation reaction was remarkably observed. Thus, it was indicated that the condensation reaction would occur after the woody constituents were degraded to a certain extent.

The phenol concentration was gradually decreased when the condensation reaction was not observed under the mild reaction condition. It was shown the phenol was kept being consumed unless the condensation reaction did not take place. The phenol concentration was compared between in the presence of remarkable condensation reaction and in the absence of it. As a result, it was found the phenol concentration was lower and became stable when the condensation reaction occurred. It indicated that the liquefaction was suppressed and the condensation reaction was prompted instead. However, in the case the condensation reaction was hardly seen, the consumption of phenol also became nearly stable, indicating the phenolation almost stopped. It was thought that if the molecules of condensing agent, such as carbocations and degraded compounds or others, were large, the condensation reaction was not likely to occur. In other words, the cause of the condensation reaction was considered to be not only the lowering of phenol concentration but also the degradation of liquefied woody constituents to low molecules under the intensive liquefaction conditions. Here, we suggested the possible schematic mechanism of the initial condensation reaction in this study as it is shown in figure 7.

Based on the results of this study, it can be said that wood liquefaction must be carried out under mild condition, and much more phenol should be added in order to prevent the condensation reaction. However, long reaction time will be needed for mild liquefaction conditions to liquefy the woody constituents well. And phenol addition should be limited because it is made from petroleum. Therefore, the condensation reaction should be prevented maintaining the reaction condition as suitable for protection of environment. Lee and Wang [14] found that the condensation reaction can be inhibited by adding water to the 


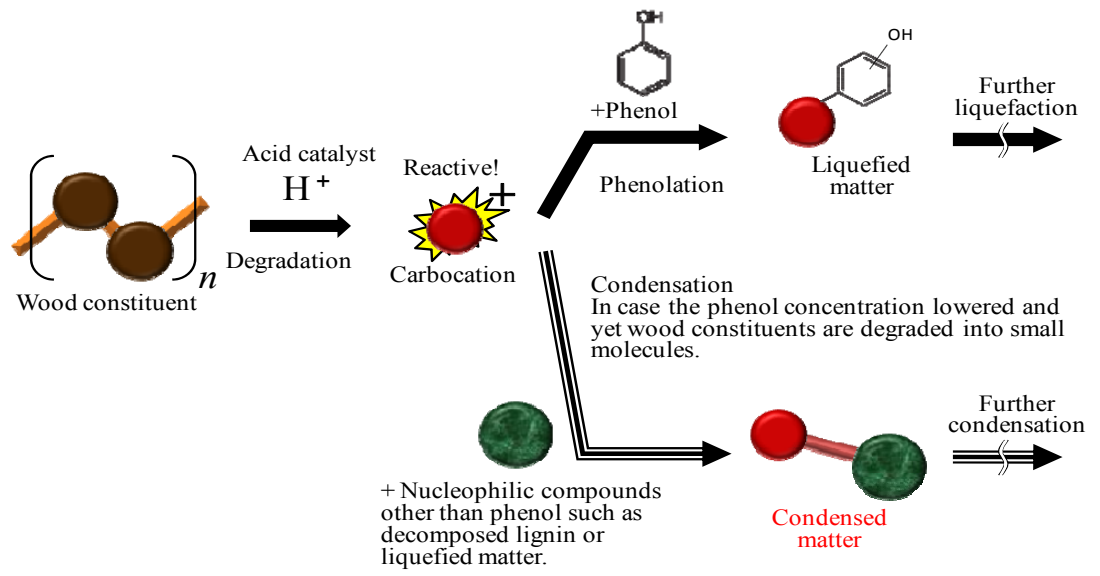

Figure 7: Possible schematic mechanism of the initial condensation during the liquefaction of woody materials with phenol.

wood liquefaction system but the quality of phenolic resin was slightly inferior to a commercial resin. We will report a new method for preventing the condensation reaction later.

\section{Acknowledgement}

Some works of this study were supported by the special funds for Basic Researches (B) (No. 22404022, FY2010-2012) of Grant-in-Aid for Scientific Research of the Japanese Ministry of Education, Culture, Sports, Science and Technology (MEXT), Japan.

\section{References}

[1] G. Li, T. Qin, Novolak type phenol formaldehyde resin from Waste brownrotted wood, Advanced Material Research, 217-218, 490-494, 2011.

[2] S. H. Lee, Y. Teramoto, N. Shiraishi, Resol-type phenolic resin from liquefied phenolated wood and its application to phenolic foam, Journal of Applied Polymer Science, 84, 468-472, 2001.

[3] X. Ma, G. Zhao, Structure and performance of fibers prepared from liquefied wood in phenol, Fibers and Polymers, 9, 405-409, 2008.

[4] Q. Wang, Q. Chen, P. Apaer, N. Kashiwagi, H. Kurokawa, K. Sugiyama, $\mathrm{X}$. Wang and $\mathrm{X}$. Guo, Liquefaction processes and characterization of liquefied products from waste woody materials in different acidic catalysts, The Sustainable World, Ecology and the Environment, 142, 343-354, 2010.

[5] Q. Wang, Q. Chen, P. Apaer, Q. Qian, T. Maezono, N. Mitsumura, H. Kurokawa, and X. Guo, Characterization of liquefied products from model woody components in the presence of mineral acid catalysts, Sustainable Chemistry, Ecology and the Environment, 154, 187-198, 2011. 
[6] M. Kobayashi, T. Asano, M. Kajiyama, B. Tomita, Analysis on residue formation during wood liquefaction with polyhydric alcohol, Journal of wood science, 50, 407-414, 2004.

[7] Y. Zhang, A. Ikeda, N. Hori, A. Takemura, H. Ono, T. Yamada, Characterization of liquefied product from cellulose with phenol in the presence of sulfuric acid, Bioresource, 97, 313-321, 2006.

[8] Lin, L., Yao, Y., Yoshioka M., Shiraishi, N., Liquefaction mechanism of cellulose in the presence of phenol under acid catalysis, Carbohydrate polymers, 57, 123-129, 2004.

[9] L. Lin, Y. Yao, N. Shiraishi, Liquefaction mechanism of $\beta-O-4$ lignin model compound in the presence of phenol under acid catalysis. Part 2.Rreaction behavior and pathway, Holzforschung, 55, 625-630, 2001.

[10] S. P. Mun, J. P. Jang, Liquefaction of cellulose in the presence of phenol using $p$-toluene sulfonic acid as a catalyst, Journal of Industrial and Engineering Chemistry, 15, 743-747, 2009.

[11] H. Ono, Y. Zhang, T. Yamada, Dissolving behavior and fate of cellulose in phenol liquefaction, Transactions of the Materials Research Society of Japan, 26, 807-812, 2001.

[12] Y. Kurimoto, S. Doi, Y. Tamura, Species effects on wood- liquefaction in polyhydric alcohols, Holzforschung, 53, 617-622, 1999.

[13] M. H. Alma, M. Yoshioka, Y. Yao, N. Shiraishi, Preparation of sulfuric acid-catalyzed phenolated wood resin, Wood science and technology, 32, 297-308, 1998.

[14] S. H. Lee, S. Wang, Effect of water on wood liquefaction and the properties of phenolated wood, Holzforschung, 59, 628-624, 2005. 